\title{
Designing and Evaluating an Innovative Solar Air Collector with Transpired Absorber and Cover
}

\author{
Ali Zomorodian and Maryam Zamanian \\ Department of Agricultural Engineering, Shiraz University, Iran \\ Correspondence should be addressed to Ali Zomorodian, zomorod@shirazu.ac.ir \\ Received 29 April 2012; Accepted 8 July 2012 \\ Academic Editors: E. R. Bandala and S. Rehman
}

Copyright ( $) 2012$ A. Zomorodian and M. Zamanian. This is an open access article distributed under the Creative Commons Attribution License, which permits unrestricted use, distribution, and reproduction in any medium, provided the original work is properly cited.

\begin{abstract}
Applying solar collectors is a popular tool for harnessing solar energy. In this work, a flat plate solar air collector was investigated under direct solar radiation in an endeavor to enhance the thermal efficiency of solar air collector with a slatted glass cover, perforated absorber aluminum sheets (porosity $0.0177,0.0314$ and absorber thickness of $1.25,2.5 \mathrm{~mm}$ ) which is the most suitable for a solar dryer. The effects of porosity and thickness on absorber performance of collector were evaluated. Six levels of air mass flow rates $\left(0.0056\right.$ to $\left.0.0385 \mathrm{~kg} \mathrm{~m}^{-2} \mathrm{~s}^{-1}\right)$ were adopted. The tests were conducted in three replications on very clear sky days in September and October. The experimental results showed that thermal efficiency of collector was increased by an increase in the porosity of the absorber. The absorber with lower porosity showed a better thermal efficiency at lower air mass flux. In the minimum air flow rate, absorber efficiency with porosity 0.0177 and 0.0314 was 0.31 and 0.29 , respectively, whereas at the maximum flow, efficiency showed an enormous change of 0.83 and 0.88 , respectively. This solar air heater can be used for drying agricultural products, heating the space of greenhouse, and so forth.
\end{abstract}

\section{Introduction}

Solar air heaters are inherently low in thermal efficiency due to low heat capacity and low thermal conductivity of the air in comparison to the liquid-type solar collectors [1]. Many researchers have tried to enhance the efficiency of the solar air heaters through providing an intimate heat transfer between air and absorbing media. The main problem is low heat transfer coefficient between the absorber and air which reduces the thermal efficiency [2]. Design improvement of solar collectors would lead to better performance of system. Various absorber plates and glazing systems have been used in solar collectors and reported in the literature, porous (transpired) absorber and nonporous one and different types of glazing. The main disadvantage of nonporous absorber is depletion of complete heat transfer between absorber and fluid that leads to low thermal efficiency because the coefficient of convective heat transfer between air and the absorber plate is quite low, therefore, the temperature of the absorber plate would be high and radiation loss is quite large. In porous type, absorbing the solar radiant heat and the heat convection between air and the absorber can effectively strengthen the air that passes through the collector absorber which improve the quality of heat transfer coefficient and thermal efficiency, therefore it would be better in thermal characteristics in comparison with nonporous absorber collector [3]. Porous absorber plates have been studied in different studies such as absorber made of aluminum foil cutted [4], wire nets [5,6], retail glass [7], pieces of coal [8], hollow spheres [9], pages made of black synthetic fiber [10], and thick black cotton fabric [11]. The advantage of porous absorber is attributed to the lower thermal energy dissipation to environment due to absorption and penetration depth of solar radiation [1].

In a study conducted by Whilier, 1964 [12], on solar air collector it was found that the use of a transparent coating layer is necessary to increase the economic efficiency of the collector. Zomorodian et al., 2001 [11], studied a collector with thick black cotton fabric absorber and slatted glass cover with vertical distance between the slatted glass sheets (transpired cover) 3, 5, 7 and $9 \mathrm{~mm}$ to reduce heat loss from the upper part of collector and to increase the thermal efficiency. 
In a research on the effect of wind direction on thermal performance, it was found that the thermal efficiency raised when the wind was perpendicular to the direction of grooves and the lowest one occurred when the wind was blowing along the grooves. The effect of this wind direction change was about 10 to 20 percent on thermal efficiency [13].

Using the FLUENT software to evaluate the numerical grid plates with heat transfer in parallel flow to the suction, it was revealed that thermal performance was dependent on the six dimensionless parameters. One of these dimension groups was $x=t / D$, the ratio of thickness to hole diameter. Increasing this parameter raised the heat transfer surface area within the hole thus more heat transfer into the absorbing plate and resulted in an increase in the thermal efficiency of the absorber [14].

To enhance the heat transfer coefficient between the absorber and the air, three perforated aluminum sheets were evaluated with different porosities and thickness of $1.25 \mathrm{~mm}$. To reduce heat losses from the upper surface, one layer of plain glass sheet cover was used. The results of this study introduced the two better porosities for absorber sheets for better thermal efficiencies under different operating conditions [15].

In order to decrease the radiation and convection losses and reduce the high effect of air stream blowing on the top of the collector and blowing direction, the present research was conducted on a slatted glass sheet cover (transpired cover) with metallic transpired absorber solar air heater for outdoor conditions.

\section{Materials and Methods}

This transpired solar air collector consisted of an optically transparent layer of several narrow glass sheets shaped in slatted form as a double glazing collector cover, a porous aluminum sheet absorber, a pressed wood framework covered by the bottom layer of insulation made of glass wool with a thickness of $50 \mathrm{~mm}$. The pilot size experimental collector was illustrated in Figure 1.

2.1. Glass Cover. The inlet air was introduced through the slots formed by the slatted collector cover. This air sucking recovers part of the short wavelength radiation absorbed by the glass sheets and causes a better cooling action for the pieces of glass sheet cover. Moreover, since the air passes downward throughout the absorber with more uniformly distributed pattern, the absorber plate would be more uniformly cooled by cooling fluid. Ten glass sheets $(20 \times$ $70 \mathrm{~cm}$ ) with thickness of $4 \mathrm{~mm}$ and slot vertical distance (air gap) of $4 \mathrm{~mm}$ were used as a double glazing slatted glass cover [11] as in Figures 2 and 3.

2.2. Absorber Plate. In this study two porous aluminum absorbers with effective surface area $106 \times 75 \mathrm{~cm}$, porosity $P_{1}=0.0177$ (hole diameter $3 \mathrm{~mm}$ and pitch of $2 \mathrm{~cm}$ ) and $P_{2}=0.0314$ (hole diameter $2 \mathrm{~mm}$ and pitch of $1 \mathrm{~cm}$ ) and thicknesses of $t_{1}=1.25$ and $t_{2}=2.5 \mathrm{~mm}$ were used to investigate the porosity and thickness effect on collector thermal efficiency. Arrangements of the holes on

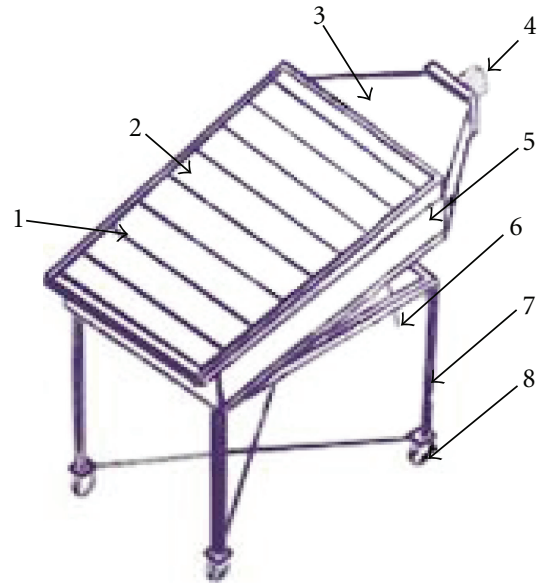

(1) Cool air inlet

(2) Slatted glass cover

(3) Air reducer

(4) Hot air outlet
(5) Body

(6) Adjustable tilt angle mechanism

(7) Stand

(8) Carrier wheel
FIGURE 1: An overview sketch of the new solar collector.

both absorbers were on square pattern as in Figure 4. The absorber surfaces were then painted matt black.

2.3. Absorber Installation. In order to maintain a uniform air flow rate through the absorber plate, along and across the air flow direction, cross section area between the absorber and glass cover in the direction of flow was kept constant, $A_{1}=$ $A_{2}$, as in Figure 2 .

Absorber was assembled into the collector body as a slanted plate. To install the glass cover, a rectangular-shaped wooden frame was made (internal dimensions $70 \times 105 \mathrm{~cm}$, height of front wall $2 \mathrm{~cm}$, and the height of back wall $9 \mathrm{~cm}$ ), Figure 3. To install the body of collector as well as the air reducer, a stool made of metal cornerstone with length, width, and height 105, 70, $65 \mathrm{~cm}$, respectively, was erected. This wheeled carrier was also used for altering the angle of absorber plate to south, as in Figure 1.

2.4. Instrumentations. In this study, 12 smart temperature sensors (SMT-160 $\pm 0.5^{\circ} \mathrm{C}$ ) were used for measuring the temperature of different locations of the absorber, inlet, and exhaust air. Two sensors at the slot air inlet, a sensor at the air exit and the six at the top and bottom of the absorber plate symmetrically just near the absorber holes to measure the air temperature before and after passing through the porous absorber. Along the airflow direction three shaded sensors were installed on the absorber plate to monitor the absorber body temperature.

A constant speed centrifugal fan (Parma, $1400 \mathrm{rpm}$, $50 \mathrm{~Hz}$, Italy) was used as an air flow source connected to an inverter (N50-015SF, $1.5 \mathrm{kw}$, Korea) for altering the air flow rate. The air flow velocity was measured using an anemometer (Lutron, Taiwan) in a PVC pipe $(10 \mathrm{~cm}$ ID) connected to the output duct of collector. The air flow velocity was converted to air flow rate by multiplying the mean air flow velocity by inside air duct cross section area. 


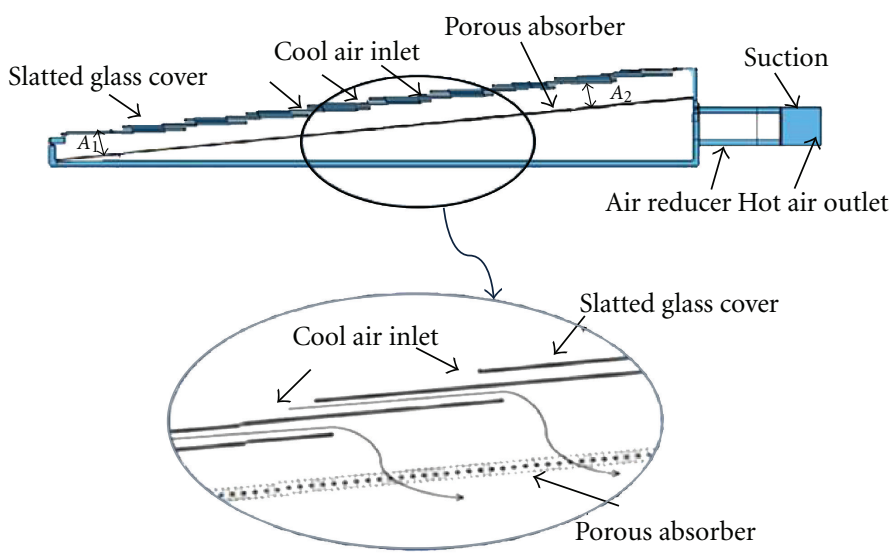

FIgURe 2: Side view of slatted glass cover.

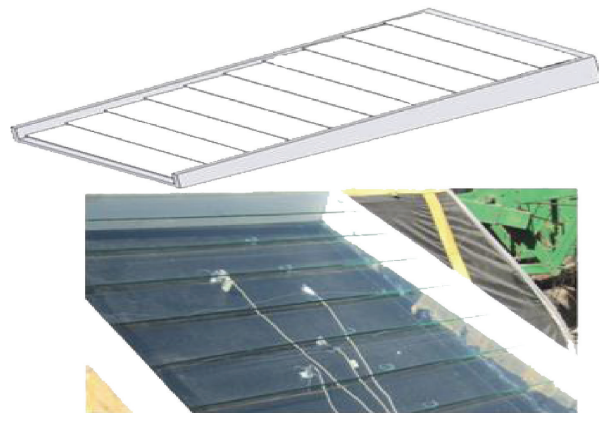

Figure 3: Slatted glass cover and the connected sensors.
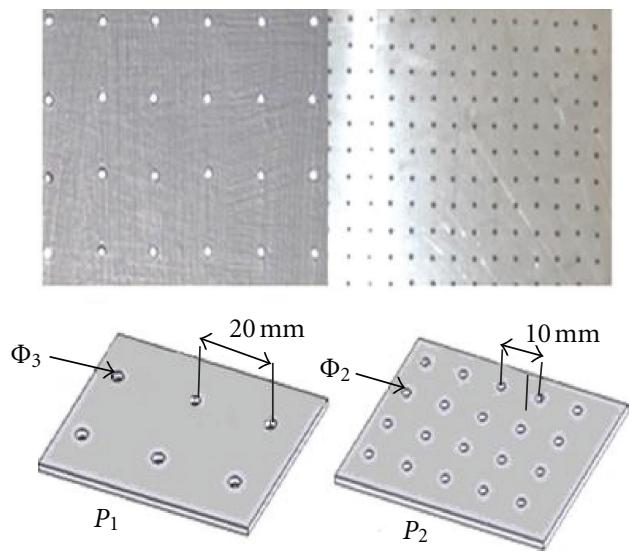

FIgURe 4: Absorber plates and their porosities.

Furthermore, a silicon type pyranometer (Caselia, w, 0-2000 $\pm 1 \mathrm{w}, \mathrm{UK})$ was used to measure solar radiation intensity.

2.5. Experimental Procedure. The test rig was located on Faculty of Agriculture at Shiraz University. The inclination of collector and pyranometer by considering (1) and according to 30 degree latitude of shiraz, was set on 45 degree towards the south [1]

$$
\alpha=\text { local altitude }+15 \text {. }
$$

TABLE 1: Test factors variance analysis of collector efficiency.

\begin{tabular}{lccc}
\hline Variable & df & Sum of squares & $F$ \\
\hline$F$ & 5 & 2.781 & $15322.199^{* *}$ \\
$P$ & 1 & 0.009 & $242.393^{* *}$ \\
Th & 1 & 0.006 & $177.936^{* *}$ \\
$F * P$ & 5 & 0.015 & $84.428^{* *}$ \\
$F * T h$ & 5 & 0.001 & $7.517^{* *}$ \\
$P * T h$ & 1 & 0.000 & 4.972 \\
$F * P * T h$ & 5 & 0.001 & 3.168 \\
Error & 48 & 0.002 & \\
\hline
\end{tabular}

** Significance level of $1 \%$.

In each set of experiments (each absorber) thermal efficiency of collector was measured for six levels of air flow rate $\left(0.0056,0.0118,0.018,0.0235,0.029\right.$, and $\left.0.0385 \mathrm{~kg} \mathrm{~m}^{-2} \mathrm{~s}^{-1}\right)$. To set each flow rate, an inverter was used to alter the engine Rpm, then the fan speed was changed and different flow obtained.

The tests were conducted (September-October 2010) in three replications on very clear sky days during 11 to 13 o'clock assuming the sun radiation and heat condition of environment show no significant changes during this time, [16].

\section{Results and Discussion}

For calculating the thermal efficiency of collector, (2) was applied

$$
\eta=\frac{\dot{m} c_{p}\left(T_{0}-T_{i}\right)}{G_{T}}
$$

In order to evaluate the significant effect of pertinent parameters on thermal efficiency, data was analyzed using SPSS software (version 16). The results were illustrated in Table 1. The results showed that the effects of air flow rate and absorber porosity and absorber thickness were very significant on solar air heater thermal efficiency. It is shown that collector thermal efficiency increases by increasing 


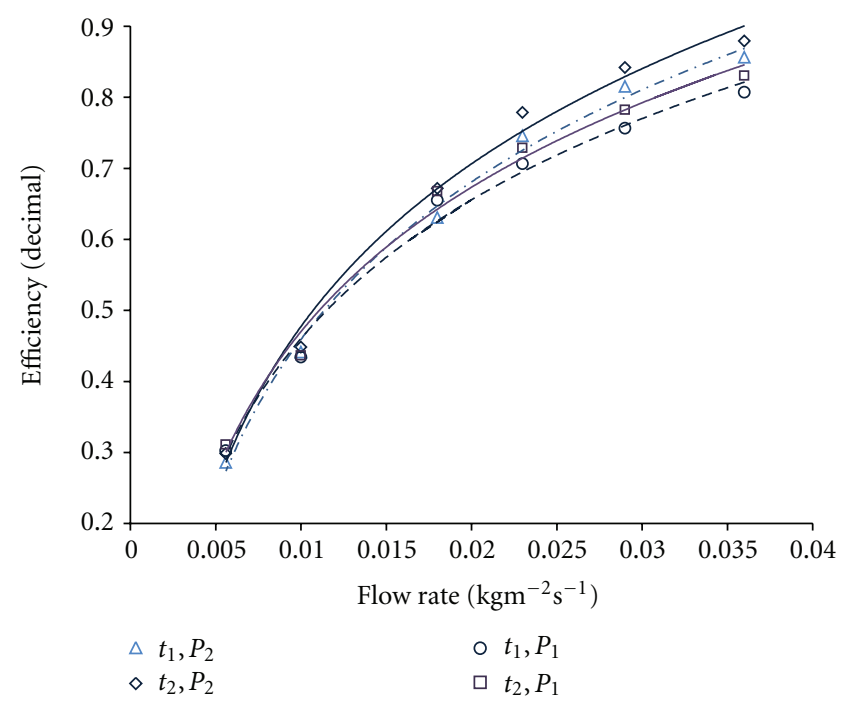

FIGURE 5: Effect of cooling air flux on collector efficiency for different perforated absorbers.

the air flow flux for four absorbers $(2$ porosities and 2 thicknesses), as in Figure 5. At low and medium air flow rates, the increasing rate is very significant whereas this trend continues at higher flow but with a diminishing rate. This trend of change was reported by many other researchers.

It can be concluded that at lower air flows, the convective heat transfer coefficient between absorber plate and cooling air has a lower order of magnitude which results in a higher absorber surface temperature. Higher absorber surface temperature boosts the convective and radiative top heat losses. These results demonstrate a very good agreement with many other researchers' investigations $[4,11]$.

Due to low heat capacity of air, a low temperature difference between cooling air and absorber which is caused at a higher air mass flux, collector efficiency increases very slowly at high air flow rates. In other words, thermal efficiency increases at higher air flow rates due to greater contact volume of air flow rate which results in high rate of heat transfer coefficient and this reduces heat losses by radiation and convection that results in increase in efficiency. Therefore, an accurate justification needs to be made between blower power and collector efficiency rise at higher air flow rates.

Referring to Figure 6, it can be concluded that by increasing the exit and ambient air temperature gradient per unit of solar insolation, the thermal efficiency shows a decrease trend in all collectors. Besides, by increasing air mass flux, the difference between exhaust and ambient air temperature decreased per unit of solar radiation results in increasing of thermal efficiency. This fact may be due to better heat transfer between porous absorber and downward sucking air and sweeping effect of cooling air through the absorber plate.

The most porous absorber plate showed a better thermal efficiency compared with the others. This fact is also revealed

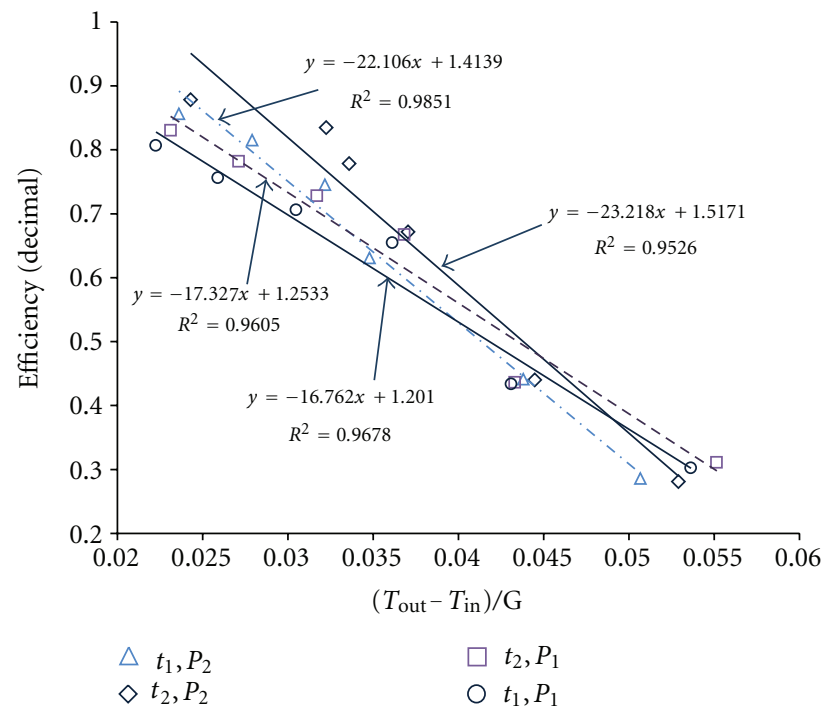

FIGURE 6: Variations of normalized air temperatures, $\left[\left(T_{\text {out }}-T_{\text {in }}\right) / G\right.$, $\left.\left({ }^{\circ} \mathrm{Cm}^{2} \mathrm{~W}^{-1}\right)\right]$, versus collector efficiency for four absorber plates.

in Figure 6 as expected. In fact these two graphs, Figures 5 and 6 , are quite confirmed by each other.

The maximum absorber thermal efficiencies of the collectors with absorber porosities of 0.0177 and 0.0314 were measured to be 0.83 and 0.88 , respectively, at the highest air flow rates for the thicker absorber.

In the minimum air flow rate, absorber efficiency with porosity 0.0177 and 0.0314 was 0.31 and 0.29 respectively. This effect may be due to the lower heat transfer coefficient and higher absorber plate temperature which resulted in more convection and radiation heat losses.

\section{Conclusions}

A slatted glass cover and air solar collector with two different perforated absorber plates, two thicknesses and under air mass flow rates of 0.0056 to $0.0385 \mathrm{~kg} \mathrm{~m}^{-2} \mathrm{~s}^{-1}$ were tested. A maximum thermal efficiency of 0.88 was achieved for the most porous and thicker absorber plate at the highest air mass flow rate, but at very low air flow rates the absorber porosity showed a reversed effect on the efficiency. The absorber with less porosity illustrated a higher efficiency.

\section{Nomenclature}

$P$ : Porosity of absorber

$\varnothing$ : Hole diameter

A: Cross section area between the absorber and glass cover

ID: Internal diameter

$\alpha$ : The tilt angle of collector and pyranometer

$\eta$ : Thermal efficiency of collector

$\dot{m}$ : Air mass flux per unit area of collector $\left(\mathrm{kg} \mathrm{s}^{-1} \mathrm{~m}^{-2}\right)$

$c_{p}$ : Air-specific heat capacity $\left(\mathrm{j} \mathrm{kg}^{-1}{ }^{\circ} \mathrm{C}^{-1}\right)$ 
$G_{T}$ : The radiation flux on the collector $\left(\mathrm{Wm}^{-2}\right)$

$T_{0}$ : Outlet air temperature $\left({ }^{\circ} \mathrm{C}\right)$

$T_{i}$ : Inlet air temperature $\left({ }^{\circ} \mathrm{C}\right)$.

\section{References}

[1] J. A. Duffie and W. A. Beckman, Solar Engineering of Thermal Processes, John Wiley, New York, NY, USA, 1991.

[2] A. A. Mohamad, "High efficiency solar air heater," Solar Energy, vol. 60, no. 2, pp. 71-76, 1997.

[3] H. Fechner and O. Bucek, "Investigations on several series produced collectors," Renewable Energy, vol. 28, pp. 293-302, 1998.

[4] J. P. Chiou, M. M. El-Wakil, and J. A. Duffie, "A slit-and expanded aluminum-foil matrix solar collector," Solar Energy, vol. 9, no. 2, pp. 73-80, 1965.

[5] W. A. Beckman, "Radiation and convection heat transfer in a porous bed," Journal of Engineering for Power, vol. 90, pp. 5154, 1968.

[6] Y. H. Hamid and W. A. Beckman, "Performance of air- cooled radatively heated," 1971.

[7] R. Collier, "The characterization of crushed glass as a transpired air heating solar collector material," in Proceedings of the Silver Jubilee Congress, vol. 1, pp. 264-268, Atlanta, Ga, USA, 1979.

[8] S. N. Singh, R. C. Birkebak, and R. M. Drake, "Laminar free convection heat transfer from downward-facing horizontal surfaces of finite dimensions," Progress in Heat and Mass Transfer, vol. 2, pp. 87-98, 1969.

[9] R. K. Swartman and O. Ogunlade, "An investigation on packed-bed collectors," Solar Energy, vol. 10, no. 3, pp. 106110, 1966.

[10] N. K. Bansal, A. Boettcher, and R. Uhlemann, "Performance of plastic solar air heating collector with a porous absorber," International Journal of Energy Research, vol. 7, no. 4, pp. 375384, 1983.

[11] A. A. Zomorodian, J. L. Woods, and M. H. Raoufat, "Performance characteristics of a transpired solar air heater," Iran Agricultural Research, vol. 20, pp. 139-154, 2001.

[12] A. Whillier, "Performance of black-painted solar air heaters of conventional design," Solar Energy, vol. 8, no. 1, pp. 31-37, 1964.

[13] A. Sotudeh, Numerical 3-D simulation of airflow along heat transfer from porous absorber under suction with different angle [M.S. dissertation], Mechanic College, University of Shiraz, 2002.

[14] A. Razavikhosroshahi, Numerical simulation study on heat transfer of porous absorber solar air collector with parallel airflow [M.S. dissertation], Mechanic College, University of Shiraz, 2003.

[15] A. Zomorodian and M. Barati, "Efficient solar air heater with perforated absorber for crop drying," Journal of Agricultural Science and Technology, vol. 12, pp. 569-577, 2010.

[16] ISO 9806-2.1998. Test Methods for Solar Collectors-Part 2: Qualification Test Procedures First Edition. 

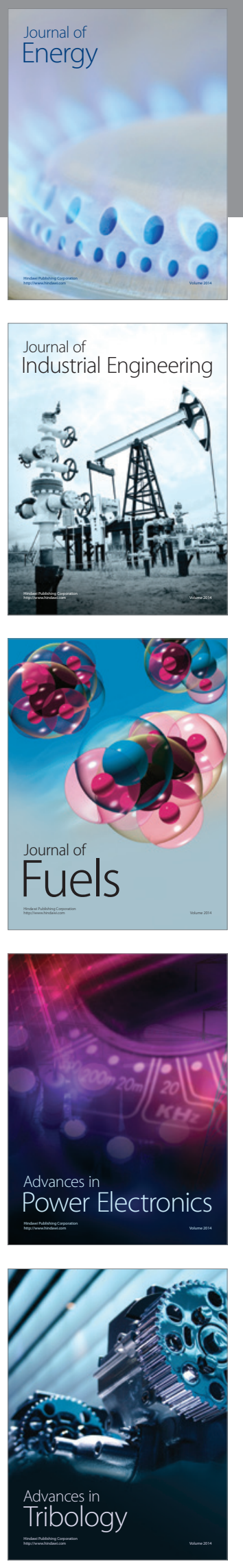
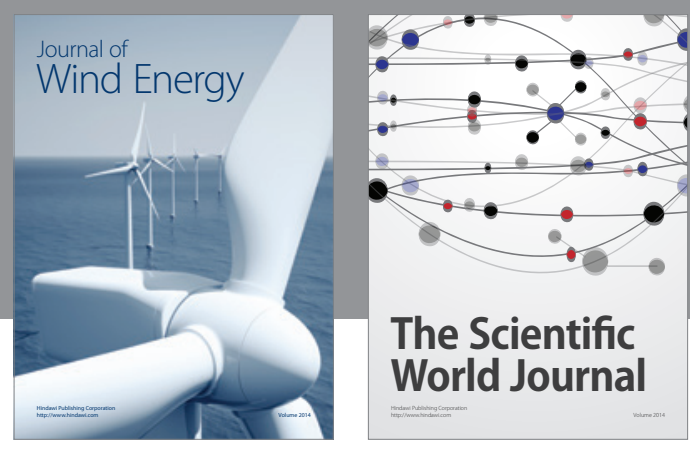

The Scientific World Journal

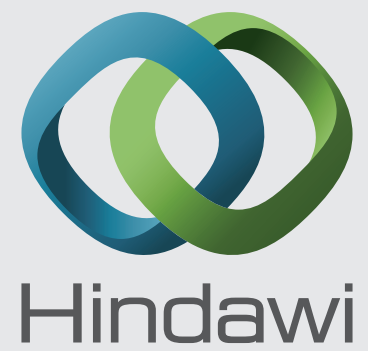

Submit your manuscripts at http://www.hindawi.com
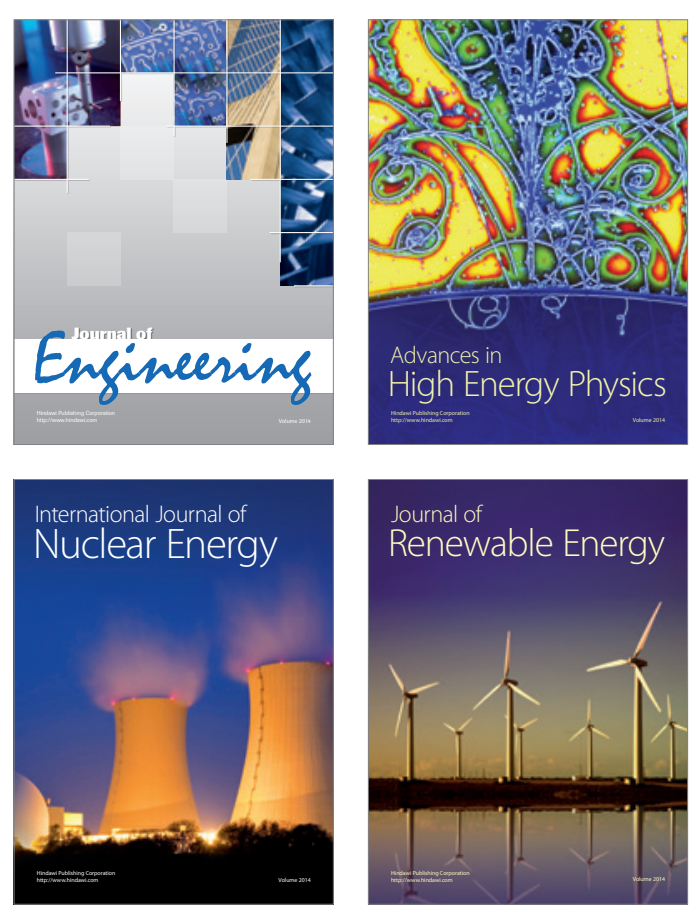

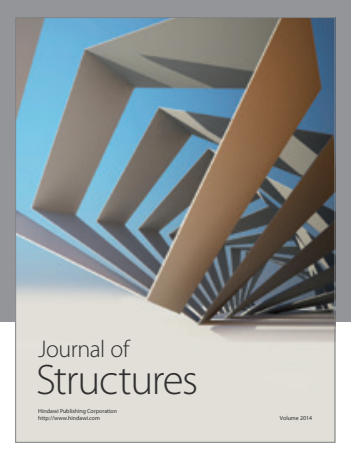

Rotating
Mechinery
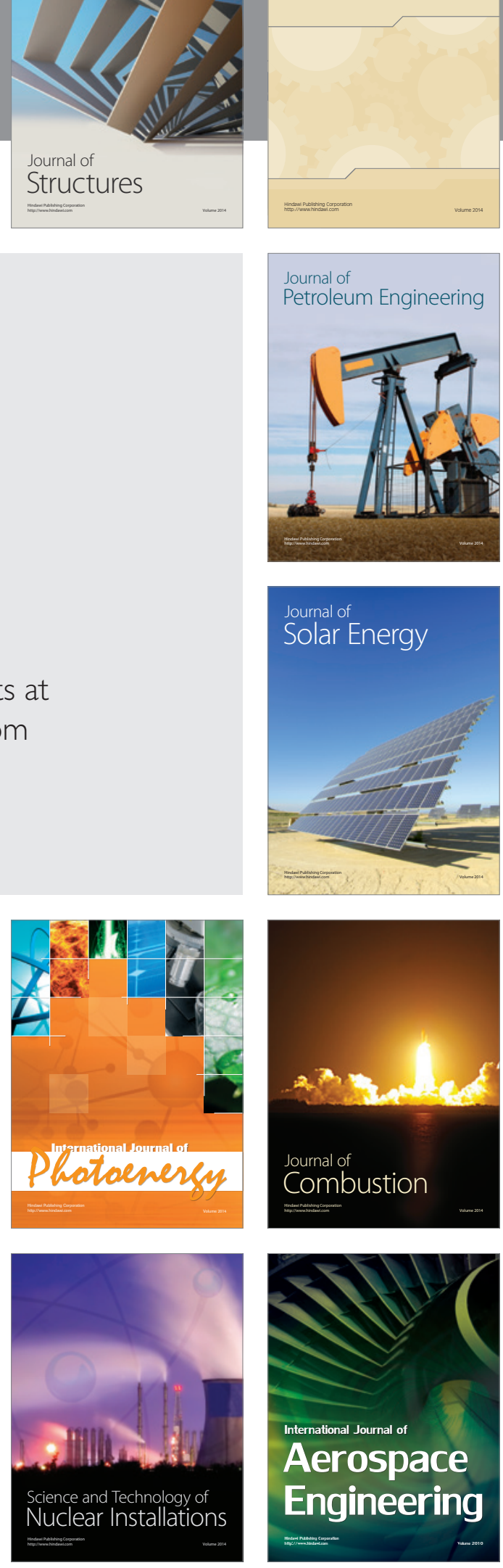